\title{
New Conceptual Solution of Joint Connection for Torsional Relief of Carrying Structure of Radial-axial Bearing at Hydraulic Excavator
}

\author{
Goran Marković $^{1^{*}}$, Milomir Gašić ${ }^{1}$, Mile Savković ${ }^{1}$, Nebojša Zdravković ${ }^{1}$ \\ ${ }^{1}$ University of Kragujevac, Faculty for Mechanical and Civil Engineering in Kraljevo
}

\begin{abstract}
Connection of revolving and nonrevolving bonds in construction and transport mechanization machines have developed under the influence of various operating and structural requirements. However, the current conceptual solutions do not provide a long and reliable life of indirect elements (bearings with big diameter). Research and development of new conceptual solutions for connection of revolving and nonrevolving bonds in construction and transport mechanization machines, in this paper are based on an analysis of torsional rigidity of various alternative solutions. Forming the theoretical calculation model of the carrying structure of radial-axial bearings has resulted in a degree of reduction of influential parameters and the theoretical dependence of corresponding geometric characteristics of carrying structure has been established. Thus, without violating the generality of the observed problem, a base has been created to research and develop the new concept for connecting revolving and nonrevolving bonds which eliminates the influence of terrain roughness on support surface deformation of radial-axial bearing.
\end{abstract}

Key words: radial-axial bearing, torsional rigidity, carrying frame, deformation

\section{INTRODUCTION}

While excavator is in function, due to roughness of leaning surface, i.e. either for ground deflection or production error, it is not possible to accomplish the complete contact between the excavator undercarriage and the leaning surface.

Namely, a machine support lifts or descends, i.e. there is redistribution of vertical reactions in supports and therefore the deformation of carrying structure (torsion) $[1,2]$. Torsion of excavator carrying structure deforms the support surface of the radial-axial bearing bond structure.

Choice of geometric values of carrying structure of radial-axial bearing can influence the structure rigidity of construction and transport mechanization machines.

This parameter has a dominanat influence on functionality and reliability of radial-axial bearing function [3]. Numerous papers dealt with the analysis of rigidity dependence and influence of geometric values of support structure relations and load transfer from revolving platform to carrying structure over the radial-axial bearing and further to leaning surface, regarding excavators, portal cranes or other machines of construction and transport mechanization $[3,4,5,6,11]$.

In this paper research and development of new concepts of connection between revolving and nonrevolving bonds in construction and transport mechanization machines was conducted in several phases, with the aim to explore and develop a new concept which improves the functions of the bonds over radial-axial bearing with big diameters (type Rothe Erde [17]) and increases reliability and speed of operations.

\section{FORMING A RESEARCH BASE FOR JOINT CONNECTION OF CARRYING STRUCTURE OF RADIAL-AXIAL BEARING AT HYDRAULIC EXCAVATOR}

Formation of the theoretical calculation model of the carrying structure of radial-axial bearings has caused a degree of reduction of influential parameters and established a theoretical dependence of corresponding geometric characteristics of carrying structure [3,13,15]. Thus, without violating the generality of the observed problems, the base for research and development of new concepts for connecting revolving and nonrevolving bonds has been created. Better machine adaptability to the terrain has been achieved by joint connection of one of the longitudinal carriers of the carrying structure of radialaxial bearing with big diameter. Such a solution avoids the appearance of support surface deformation of bearings and significantly increases its reliability, service life of the carrying structure and efficiency. The proposed conceptual solution is characterized by a simple and fast assembly and disassembly, completely disable the support surface deformation of bearings, better machine adaptability to the terrain, increased reliability and service life of the carrying structure and large-diameter bearings.

1.1 Analytic defining of rigidity dependence and influence of geometric values of support structure relation

Analytic defining of rigidity dependence and influence of geometric values of support structure relations [15] has enabled the geometric structure parameters solutions which would provide the successful track supervision and proper bond function by radial-axial bearing. 
This parameter has a dominanat influence on functionality and reliability of radial-axial bearing function. A suitable selection of the ratio of height and width coefficients of box carrier can meet the required conditions with regard to the increasing and reducing of rigidity:

- The cross section of box carrier with a constant thickness of the sheet metal ratio of moments of inertia in bending and torsion depends on the coefficient $\mathrm{k}=\mathrm{h} / \mathrm{b}$, which represents the ratio of the cross section. Percentage deviation of a range of correct values in this case does not exceed $7 \%$.The ratio of bending and torsional rigidity is defined by:

$$
E I_{X}^{\prime} / G I_{o} \approx \sqrt{3} k
$$

- If we want to perform more complex analysis of the impact of changes in the ratio of box carriers in bending and torsional rigidity, it is necessary to investigate the influence of changes in the thickness of the horizontal $\left(\delta_{2}\right)$ and vertical sheet metal $\left(\delta_{1}\right)$ on the required rigidity relation. In such an analysis it is necessary to take into account the relationship of the thickness of the horizontal and vertical sheet metals of carriers $-\lambda=\delta_{2} / \delta_{1}$. For value $\lambda=\sqrt{3} / 3$, the ratio of flexural and torsional rigidity has a minimum value. Now we can establish the relationship between the bending and torsional rigidity of cross-section, when it has a minimum value at the cross section of box carriers:

$$
\frac{E I_{X \lambda}}{G I_{o \lambda}}=2(1+v) \frac{2+\sqrt{3}}{6} k \approx 1,617 k
$$

To analyze the influences of the geometric parameters of box carriers on the relationship between flexural and torsional rigidity, when the ratio of the thickness of horizontal and vertical sheet metals is changed and when the ratio of height and width is changed, it is necessary to take the following term into account:

$$
\mu=\frac{E I}{G I_{o}}=\sqrt{3} k \lambda^{0.4}
$$

Application of the term is justified because it gives results that deviate less than $10 \%$ of the results obtained by using the correct expressions.

Depending on what support structure should meet in terms of rigidity, the choice of relationships between geometrical values of elements of the support structure makes it possible to influence the forming of the optimal structure. The change of the rigidity of the support structure at constant geometrical values, i.e. constant coefficient $\mathrm{k}$, variable coefficients $\psi=\mathrm{L}_{1} / \mathrm{L}_{2} ; \beta=\mathrm{I}_{4} / \mathrm{I}_{2}$; $\omega=\mathrm{L}_{1} / \mathrm{L}_{2} ; \varphi=\mathrm{I}_{3} / \mathrm{I}_{2}$, and for different values of $\lambda$ is given in Figs. 1 and 2. The analysis has been conducted for existing designs of the support structure (Fig. 3), and for the following values:

- constant geometrical values: $b=300 \mathrm{~mm} ; \delta=20 \mathrm{~mm}$; $\mathrm{l}_{2}=1000 \mathrm{~mm} ; \mathrm{L}_{2}=1000 \mathrm{~mm}$

- with constant coefficients $\mathrm{k}$ and $\lambda$,

- with variable coefficients

$\psi=L_{1} / L_{2} ; \omega=l_{1} / I_{2} ; \varphi=I_{3} / I_{2} ; \beta=I_{4} / I_{2} ; \eta=I_{5} / I_{2} ; I_{2}=I_{1}$ $\eta=1,0-2,5 ; \beta=1,0-2,5 ; \omega=0,4-1,0 ; \varphi=1,0-2,5 ; \psi=0-1,0$
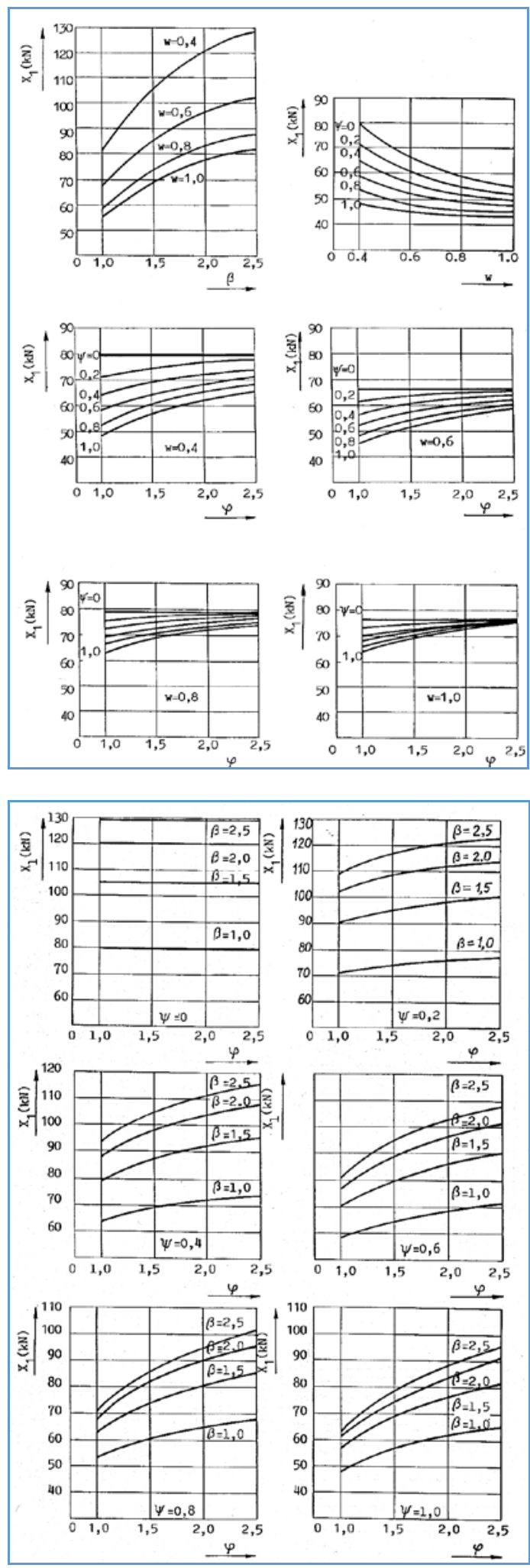

Fig. 1. Diagrams of changes in rigidity of carrying structure depending on the values of joint loads for $\lambda=1$ 

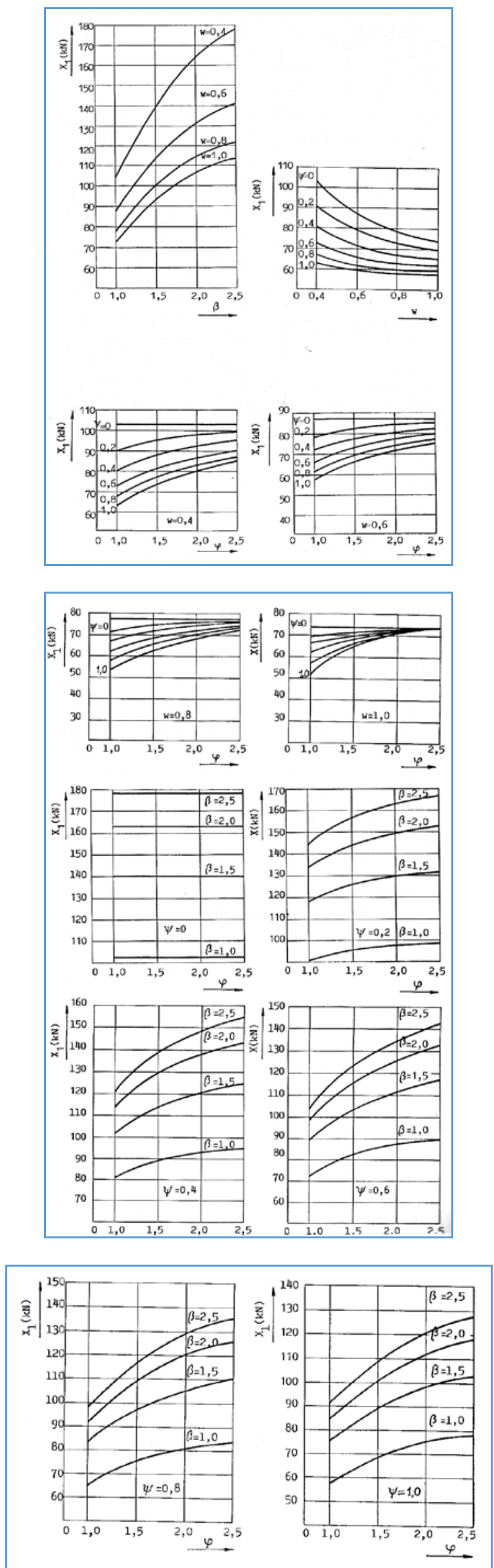

Fig.2. Diagrams of changes in rigidity of carrying structure depending on the values of joint loads for $\lambda=1,5$

[15]
Dependence of the rigidity coefficient values for $k=1 ; 2 ; 3$, with various geometric characteristics $L_{2}$ and $l_{2}(1000,2000,5000 \mathrm{~mm})$, with various parameters $\psi(0.5$, $1.0)$ and $\omega(0.5,1,0)$ is given in Fig. 4 . The values in the diagrams refer to $b=300$ mm-width of box carrier; $\delta=10$ mm thickness of vertical sheet metal and $\Delta=5 \mathrm{~mm}$ clearance between the support and the track.
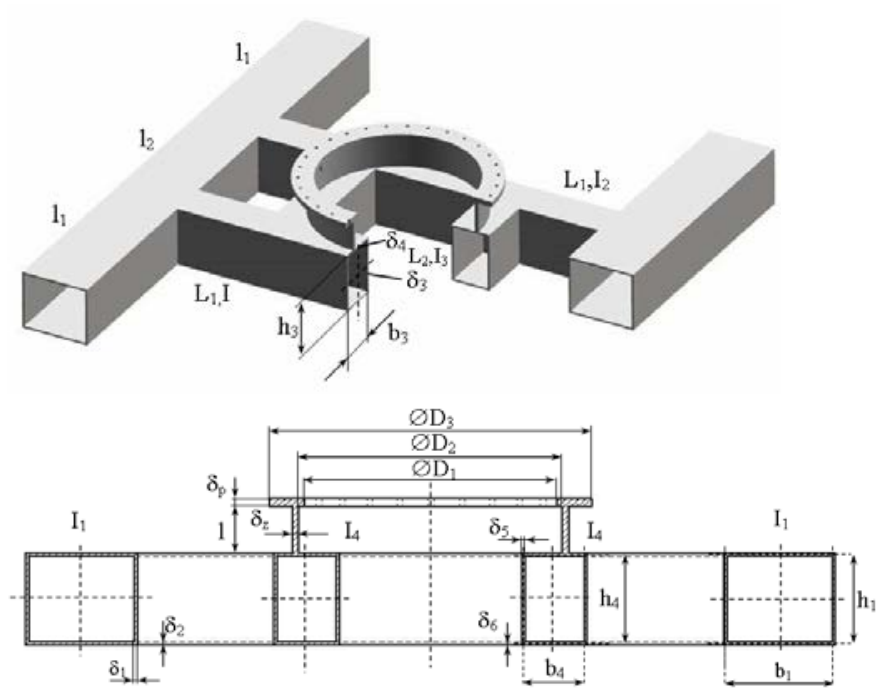

Fig.3. Proposed solution of carryng structure

It is obvious that the increase in the coefficient $\mathrm{k}$ leads to the growth of relations depending on the rigidity of the structure:

$$
\frac{C_{k i}}{C_{k j}}=\left(\frac{k_{i}}{k_{j}}\right)^{\sqrt{3}}
$$

From the diagram, it can be concluded that the previous dependence corresponds to the actual relative stiffness. This finding is of particular importance in the design, taking into account the conditions the structures must meet.

Therefore, a proper choice of the ratio of coefficients of height and width of box girder can satisfy the required conditions in terms of the stiffness increase and decrease.

Dependence of the stiffness coefficient of $\mathrm{k}=1$ and 3, with different geometrical characteristics $\mathrm{L}_{2}$ and $\mathrm{L}_{2}$ (1000, 2000, 3000, 4000 and $5000 \mathrm{~mm})$, different parameters $\psi(0,0,5,1.0)$ and $\omega(05,1.0$ or $0.4 ; 0.7)$ and at constant values $\mathrm{b}=300 \mathrm{~mm} ; \delta=10 \mathrm{~mm}, \lambda=1.5$ and $\Delta=5$ $\mathrm{mm}$ can be defined by the following expression, i.e. it can be seen that if distance $\mathrm{L}$ increases, the rigidity of the structure declines depending on:

$$
\frac{C_{L i}}{C_{L j}}=\left(\frac{L_{j}}{L_{i}}\right)^{3}
$$

On the base of these analyses, we come to a conclusion that the choice of the relations of carrying structure geometric values can make influence on: 
- increase of the rigidity of the bearing structure, and

- better supervision of the track where the machine goes, that is proper functioning of the bond between the revolving and norevolving part.

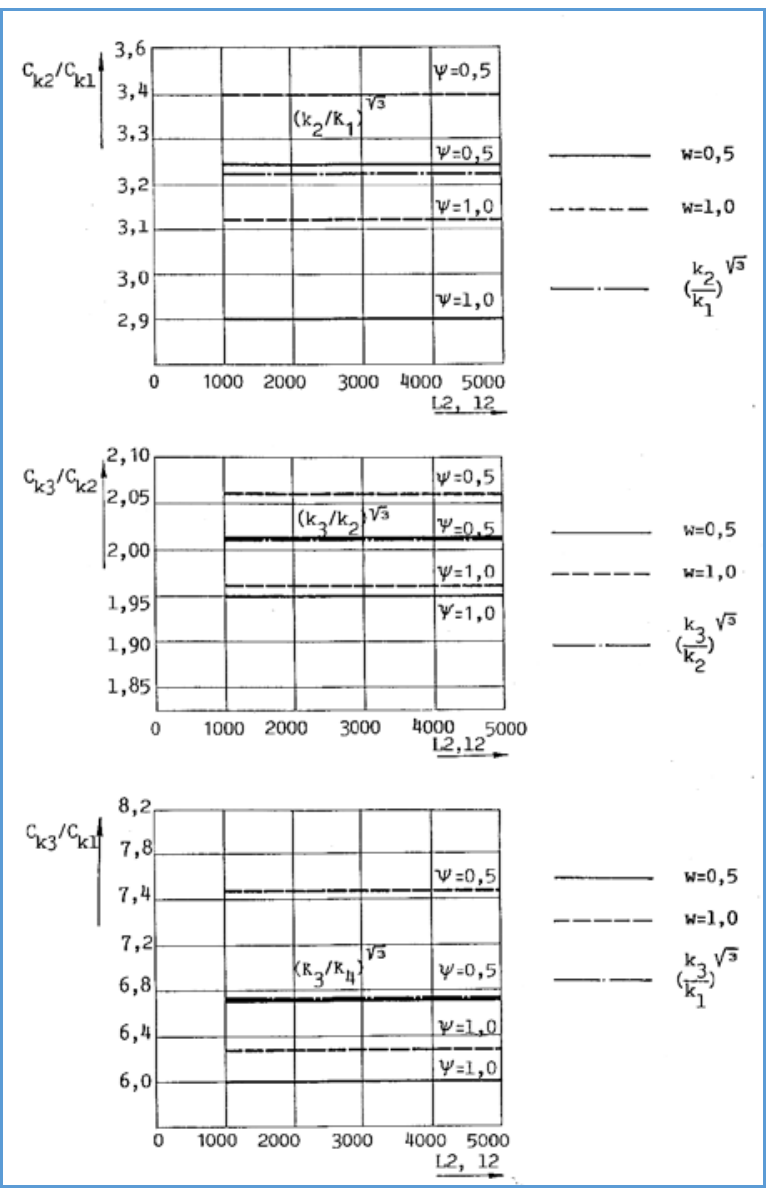

Fig.4. Diagrams of changes in rigidity of carrying structure depending on the values on coefficient $k$ [15]

However, even if the relation is defined in this way, it is not possible to provide the rigidity where the deformation of support surface would be smaller than allowed. Ingredient element, whose mounting considerably influences the effect of rigidity increase in support surface of radial-axial bearing, is cylindrical cross section carrier (Fig. 5 position 4).

The cylindrical carrier is welded on the transverse and longitudinal carrier of carrying structure and thus can further influence the reducing deformation of support surface of radial-axial bearing. The performance of the functions of the cylindrical carrier primarily depends on its geometric characteristics. By defining the necessary height $l$ and the wall thickness of cylindrical carrier $(\delta)$ it is possible to reduce deformation of support surface of radial-axial bearing with big diameter.

With the choice of a radial-axial bearing, on the basis of defined loads, it is possible for each of the family of those bearings to determine the minimum thickness of the cylindrical carrier. The expression for the thickness of the carrier should include $\mathrm{Fr}=0.25 \mathrm{r}$. The height of the cylindrical carrier should not be less than $0,5 \mathrm{r}$.
For heavy operating regime a height of the cylindrical bearing carrier should be $\mathrm{l}=\mathrm{r}$.

Having in mind the preconditions of a reliable and secure operation of the bond between the revolving and norevolving part, as well as the preferred choice of ratios of geometric values of carrying structure, it is evident that the required rigidity of support surface can be achieved by mounting an ingredient element as well as the proper selection of the bearing type.

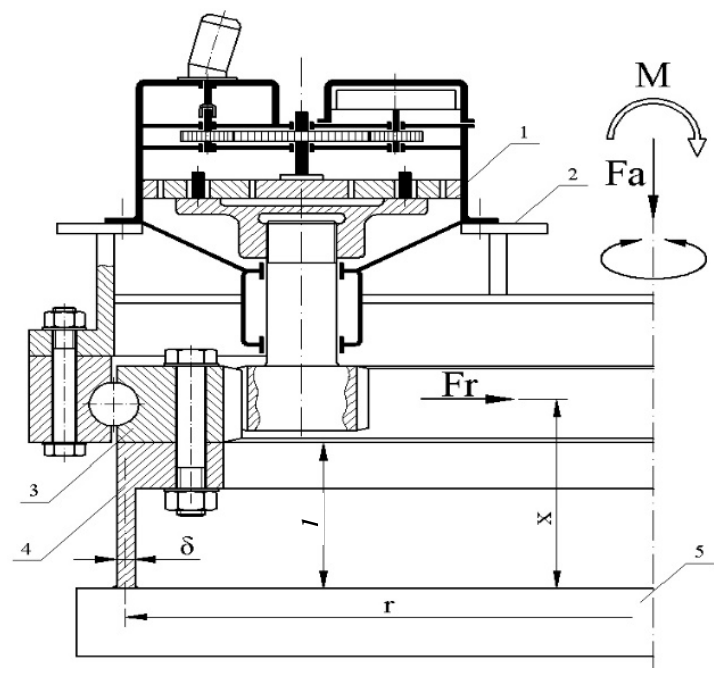

Fig.5. Radial-axial bearing with cylindric cross section carrier [13]

\subsection{Analysis of load distribution and displacement of carrying frame}

Further analysis of carrying frame of radial-axial bearing and determining the performance of revolving and nonrevolving parts bond, have been performed by determining the displacement of points of the longitudinal and transverse carriers and determining the facts whether they correspond to the set requirements in terms of proper functioning of radial-axial bearing [14].

In order to understand the influence of roughness of terrain where machine goes on support surface deformation, as well as the verifications of formerly obtained conclusions, the movements of characteristic points of support surface are obtained by considering the carrying frame with and without cylindric carrier.

By mounting the indirect element between the carrying structure and the radial-axial bearing, the effect of rigidity increase in the bearing support surface is achieved, that is the influence of terrain roughness on the bearing support surface deformation is decreased. The change in support surface deformation, with and without cylindric carrier, is given in Fig. 6.

Releasing of support (2), for the variant with and without the cylindrical ring, displacements of the characteristic points are obtained experimentally (Fig. 7).

By analyzing the values for characteristic point deformation of support surface for variants with and without cylindric carrier, its decrease can be seen, that is carrying frame rigidity is increased at indirect element mounting. 

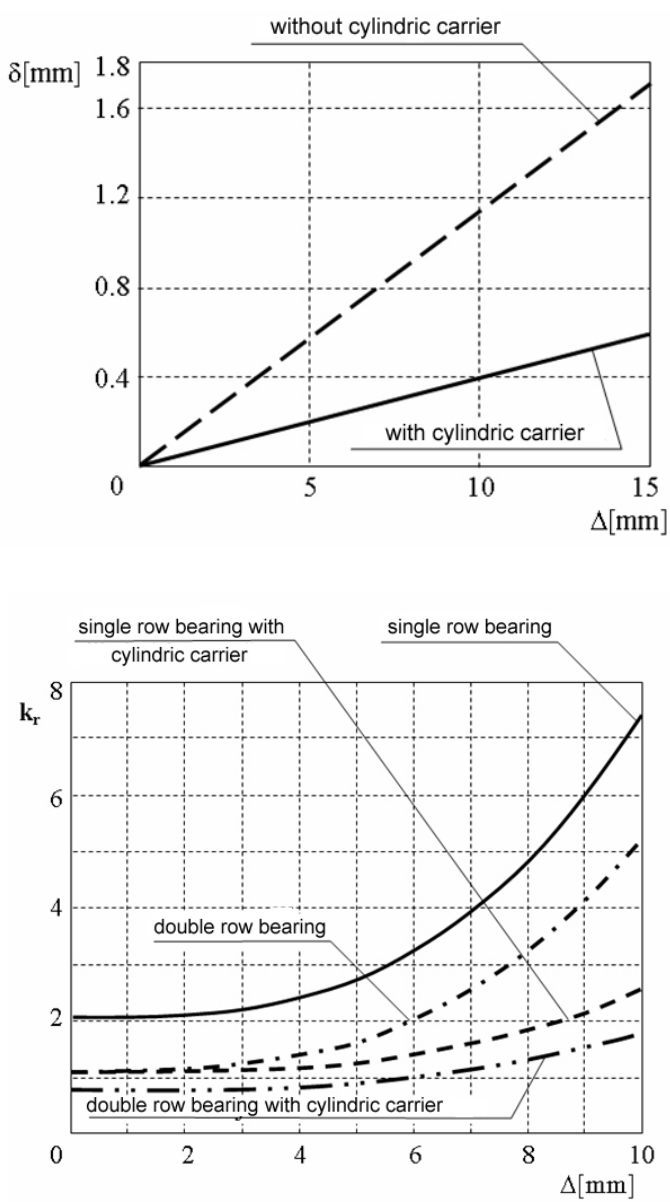

Fig. 6. Comparative diagram of carrying structure support surface deformation with and without cylindrical carrier and rigidity difference quotient dependence $k_{r}$ [13]
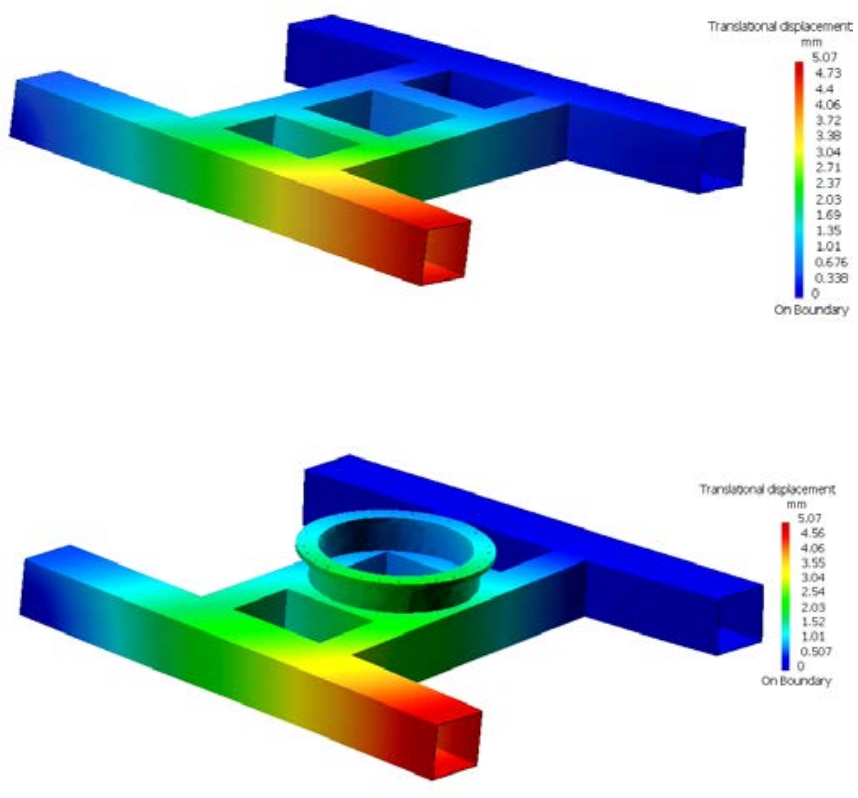

Fig.7. Movements of carrying frame points with and without cylindric carrier [13]
The influence of bearing structure, that is the bearing type, is smaller for structure variant with cylindric carrier as indirect element. We should also bear in mind the fact that the choice of radial-axial bearing depends on the load that it conveys during its exploitation.

Checking the theoretical results obtained in this case, for the known distance between the supports of the supporting frame of the physical model ( $L_{I}=2250 \mathrm{~mm} ; L_{I I}=2410 \mathrm{~mm}$ ), and defined by expression

$$
\frac{C_{L_{I}}}{C_{L_{I I}}}=\left(\frac{L_{I I}}{L_{I}}\right)^{3}=\frac{f_{I I}}{f_{I}} \Rightarrow\left(\frac{2410}{2250}\right)^{3}=\frac{-2.8888}{-2.4004} \Rightarrow 1.23 \cong 1.20
$$

shows that the results almost entirely correspond to the real values.

Also, we can prove the correctness of the defined expression:

$$
\frac{C_{k I}}{C_{k I I}}=\left(\frac{k_{I}}{k_{I I}}\right)^{\sqrt{3}}=\frac{f_{I I}}{f_{I}} \Rightarrow\left(\frac{0.857}{0.767}\right)^{\sqrt{3}}=\frac{-2.8888}{-2.4004} \Rightarrow 1.212 \cong 1.20
$$

Short conclusions of the previous analysis as a precondition for the creation of a base for research and development of new conceptual solutions for bond between revolving and nonrevolving parts without violating the generality of the observed problems are as follows:

- Experimental test results show high approval and confirm the defined theoretical dependence; - Carrying structure can not fully provide the necessary rigidity of support surface and it is not always possible to achieve smaller points movements of support surface than allowed ones despite the choise of relations between geometrical values of bearing structure elements;

- The cylindrical carrier, as the intermediate element between the bearing and the bearing frame, has a significant impact in providing the necessary rigidity of support surface of radial-axial bearing.

\section{THE JOINT CONECTION FOR TORSIONAL RELIEF OF CARRYNG STRUCTURE-CONCEPTUAL SOLUTION}

Torsional relief of carrying structure at hydraulic excavator, which largely solves the deformation problem of support surface of radial-axial bearing, is based on the concept of a new way of excavator undercarriage, as shown in Fig. 8. Carrying structure of undercarriage consists of a central welded frame 1, which is an integral element of lean ring for connection with radial-axial bearing 2. A fixed box carrier of caterpillar 3 is welded to the central carrier 1 on the one side, while on the other side, with the support plate and the central joint, a removable connection is made with another caterpillar carrier 4 , which rotates in a vertical plane.

Conceptual solution of central joint, which achieves the better adaptability of the undercarriage structure to the terrain, is presented by a cross-section A-A in Fig. 9. 


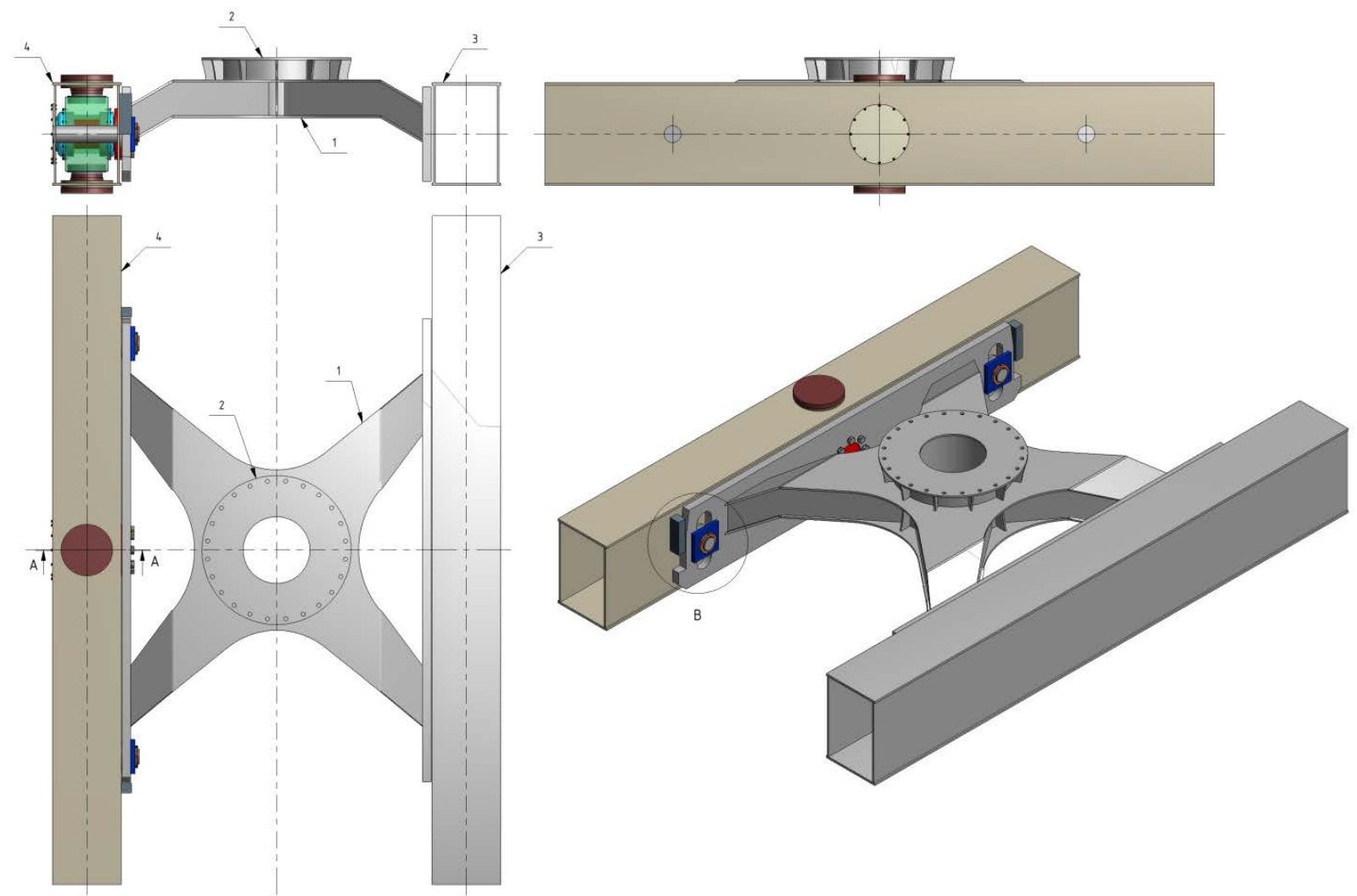

Fig.8. New conceptual solution of excavator undercarriage

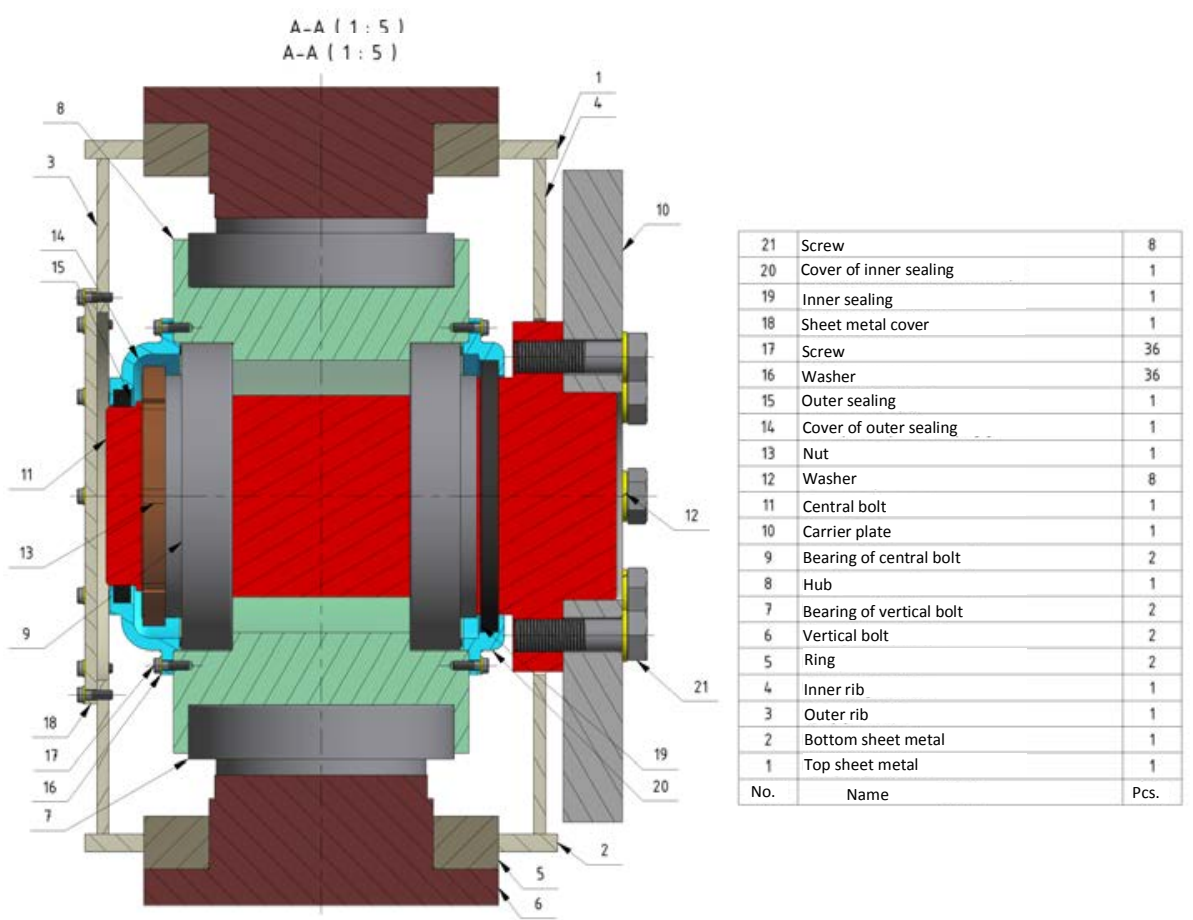

Fig.9. The layout of the central biaxial joint subassembly

Box-carrier of caterpillar, composed of an upper (1) and the lower sheet metal (2) and outer (3) and inner (4) ribs, rotates simultaneously around its horizontal and vertical axes.
The hub takes the central place in the joint assembly (8), and it has machined seats for two pairs of tapered roller bearings. 
Bearings are placed (7) on the top and bottom of the hub, in which the axle stub of vertical bolts enters (6), through which they perform the rotation around a vertical axis.

Vertical bolts are fixed to the rings (5), welded to sheet metal plates of box carriers (1) and (2).

Maneuverability around the horizontal axis is provided by a pair of tapered roller bearings (9) and the central bolt (11), which is firmly attached to the carrier plate (10) by screws (21), wherein the plate is an integral element of the welded undercarriage structure. Axial clamping of bearings is achieved with nut (13), while the sealing is provided with gaskets (15) and (19) and their covers (14) and (20), which are attached to a body of the hub (7) by screws (17).

Mounting and lubrication hole at the outer rib (3) is closed with flat cover (18).

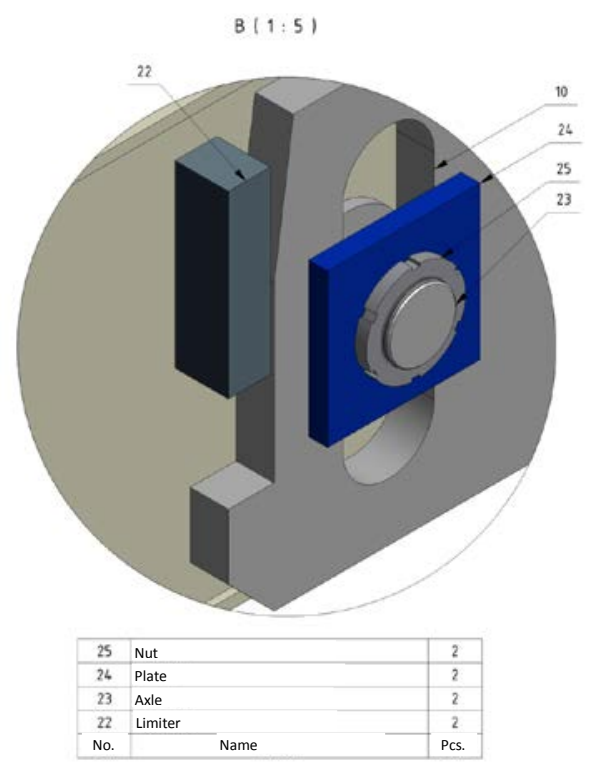

Fig. 10. Sliding couple

Maneuverability of box carrier compared to welded part of the undercarriage structure is limited with elements whose layout is shown in Fig.3 (detail B from Fig. 10). While rotating around the horizontal axis, the axle (23) welded to the ribs of a box carrier, moves inside a slot made on the carrier plate (10), wherein the slip occurs between the plate and the tiles (24), which is adjusted and tightened with nut (25). In this way guidance in the vertical plane is achieved. At the same time, these elements prevent a box carrier rotation around the vertical axis (in the horizontal plane) when excavator changes the direction of movement, while the central joint assembly relieves and the load practically is reduced to a stretching of pin (23) by forces which are created by decomposition of torque moments in a horizontal plane at force bracings.

The described solution enables rotation of box carriers in both directions in the vertical plane (Fig. 11), i.e. it enables maximum machine adaptability to the terrain. This leads to torsion relief of excavator undercarriage structure, which solves the problem of deformation of support surface of radial-axial bearing.
In order to prevent the contact of pin (23) and the wall of the slot on the carrier plate (10), the limiter is built in (22), which is welded to the inner rib (4) of a box carrier. Its location should be such that, at a limit position of carrier, it is in contact with the tooth of carrier plate (10) before making unfavorable contact pins (23) and wall of slits (Fig. 12).

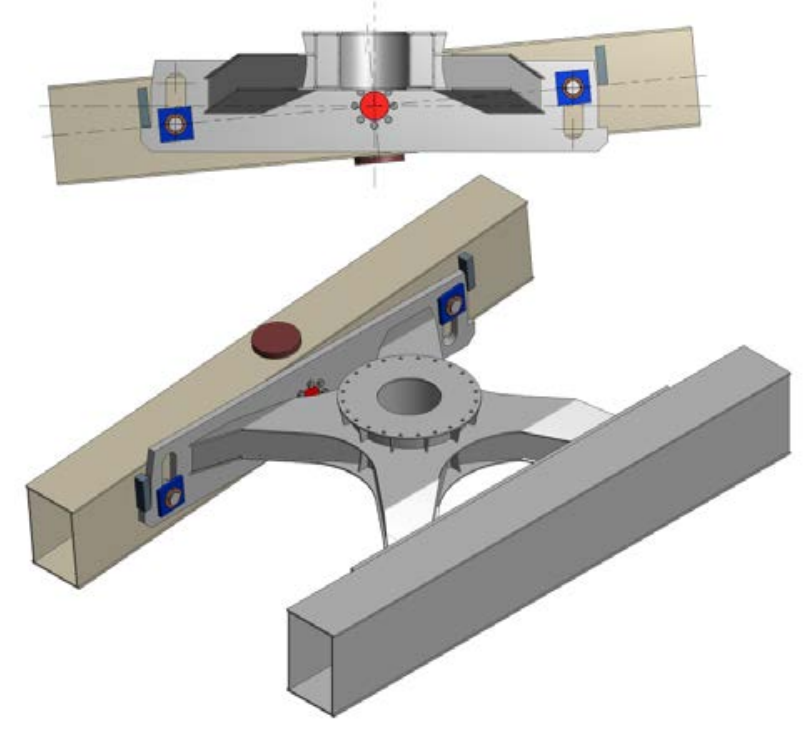

Fig.11. The effect of limiter

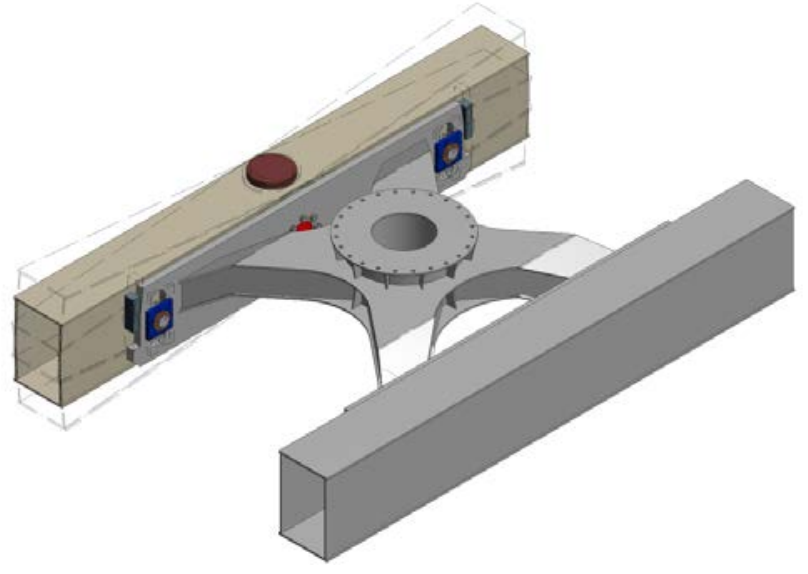

Fig.12. Adaptability of swivel carrier

\section{CONCLUSION}

Special attention in this paper is directed to the development and improvement of revolving and nonrevolving bonds in construction and transport mechanization machines, i.e. the proper functioning of the connections of these elements through the radial-axial bearing with the big diameter. Research and development of new concepts of connection between revolving and nonrevolving bonds in construction and transport mechanization machines are based on an analysis of torsional rigidity of various alternative solutions and the formation of a theoretical calculation model of the bearing support structure. 
Based on the theoretical dependence of corresponding geometric characteristics of the support structure and comparative analysis of the size of displacement of characteristic points of support surfaces, the influence of the installed cylindrical carrier on reduction of deformation and point's displacement of support surface of radial-axial bearing has been determined. The installed cylindrical carrier does not always make it possible to achieve displacements which are less than allowed ones, and the stability of the excavator at work is partly reduced, too.

Developed conceptual design prevents the appearance of deformation of support surface of radialaxial bearing which significantly increases its reliability, service life of the structure and efficiency. Easy installation of bearing elements and increased stability of the whole structure with its own boundary parameters provide the advantage compared to other ways of undercarriage structure, and consequently justifies further analysis and improvement of new solutions.

Justification of analysis and research in order to increase the life of these machines and safety in the work is even greater if the problems in transferring the load from the rotating to the nonrotating parts of the carrying structures in construction and transport mechanization machines are considered.

\section{AKNOWLEDGMENT}

This paper is part of the research included in the project TR35038 supported by Ministry of Education, Science and Technological Development of Republic Serbia.

\section{REFERENCES}

[1] Jevtić, D., Gašić, M.: The influence of relation between elements geometric dimensions of a dredger supporting structure and the connection with the rotating platform, International conference on engineering design, IECD, Dubrovnik, 1990, pp. 2343.

[2] Gašić, M., Marković, G., Savković, M.: Prilog razvoju novog rešenja veze okretnog i neokretnog dela mašina građevinske i transportne mehanizacije, IMK 14 Istraživanje i razvoj, 2005, (20-21), 12/2005, str. 71-75.

[3] Gašić, M., Savković M., Marković G., Zdravković, N.: Analiza metoda proračuna prstenova portalnog krana i bagera guseničara, IMK-14 - Istraživanje i razvoj, (30-31) 1-2/2009, str. 37-41.

[4] Amasorrain, J.I., Sagartzazu, X., Damian, J.: Load distribution in a four contact-point slewing bearing, Mechanism and Machine Theory, 2003, Vol 38, No. 4, pp. 399-412.

[5] Zupan, S., Prebil, I.: Carrying angle and carrying capacity of a large single row ball bearings as a function of geometry parametars of rolling contact and the supporting structure stiffness, Mechanism and Machine Theory, 2001, Vol 36, No. 4, pp. 399412.
[6] Prebil, I., Zupan, S., Lučić, P.: Load distribution onto rolling elements of a rotational connection, Third International Congress on Air-and Structure Borne Sound and Vibration,Montreal 1994, VDI-Berichte, pp. 23-43.

[7] Smolnicki, T., Derlukiewicz, D., Stanco, M.(2008).Evaluation of load distribution in the superstructure rotation joint of single-bucket caterpillar excavators,Automation in construction, vol. no. 17 , p.218-223.

[8] Smolnicki, T. Rusinski, E. (2007). SuperelementBased Modeling of Load Distribution in Large-Size Slewing Bearings. Journal of Mmechanical Design, vol no. 129, p. 459-463.

[9] Kania, L. (2006). Modeling of rollers in calculation of slewing bearing with the use of finite elements,Mechanism and Machine Theory. vol. no. 41, pp.1359-1376.

[10] Гашич М., Маркович Г., Савкович М.: Воздействие конструктинвых решений металической конструкции ескаватора на повышение функционалъности и долговечности радиалъно-упорного подшипника для связи оборотной платформы, Международная научнотехническая конференция "ИНТЕРСТРОИМЕХ2004“ - Сборник статей (дополнение),Воронеж, 2004. стр.7-9.

[11] Gašić, M., Karamarković, V., Savković, M., Marković, G.: Research and development of new solution to the connection of excavator carrying construction, International Conference -Heavy Machinery HM 2002, Kraljevo, 2002. pp. A3 $\div$ A5.

[12] Janošević, D.: Izbor aksijalnog ležaja pogona obrtne platforme hidrauličkih bagera, IMK 14 Istraživanje i razvoj, 2003, Vol. 16, 26-27, str. 143-149.

[13] Gašić M., Savković M., Marković G., Zdravković N.,: Research and development of carrying structure of radial - axial bearing of construction and transport mechanization machines, KOD 2010 - The 6th International Symposium, pp.41-48, Palić, 2010.

[14] Gašić M., Savković M., Marković G., Zdravković N.: Analysis of Carrying Structure Influential Parameters on Bond Function of Revolving and Non-Revolving Parts, 11th International Conference Research and Development in Mechanical Industry - RaDMI 2011, Volume 1, pp. 167-173, Soko Banja, 2011,

[15] Milomir Gašić, Mile Savković, Goran Marković, Nebojša Zdravković: Geometric Identification of Carryng Frame of Radial-axial Bearing at Hydraulic Excavators, IMK14 - Reasearch\&Developement in Heavy Machinery, Vol. 20,No 2, 47-53, 2014.

[16] Gašić, M., Savković, M., Marković G., Zdravković N.:Zglobna veza za torziono rasterećenje konstrukcije hodnog stroja bagera, Fakultet za mašinstvo i građevinarstvo u Kraljevu, IMK 14. oktobar u restruktuiranju-Kruševac, Prototip, 2014.

[17] http://www.rotheerde.com/download/info/Rothe_Erd e_GWL_D.pdf 